\title{
Change assessment of forest cover in Ghodaghodi lake area in Kailali district of Nepal
}

\begin{abstract}
S. Khanal ${ }^{1}$
Ghodaghodi Lake in Far-West Nepal has been listed as a Ramsar Site due to its significance as a habitat for several endangered species of flora and fauna. The wetland and its surrounding area is facing deforestation, forest degradation and encroachment. In this case study, unsupervised and finally supervised classification of multi-temporal Landsat imagery covering the wetland area was applied. A post-classification comparison approach was used to derive forest cover change maps. The results depicted the loss of forest cover over a thirty- one year period, in three time slices. The highest rate of loss was observed in the 1990 to1999 time slice.
\end{abstract}

Keywords: Change detection, forest cover, Ghodaghodi lake, Landsat

L and cover change detection and updating of land cover maps is a prerequisite to understand the land cover change dynamics and for the sustainable management of natural resources. Since wetlands are a critical habitat for diverse flora and fauna, including endangered species, understanding of landuse dynamics would be useful for devising effective conservation and management activities. Change detection, which encompasses identification of differences in the state of real-world entities or phenomena under consideration at different times, can be performed by comparing multi-date maps or remotely sensed images. Its capability for providing synoptic coverage and the repeatability of the provided data makes earth remote sensing a cost effective (Bauer et al., 2003) and widely used method for change monitoring ( $\mathrm{Lu}$ et al., 2004). The present study used multi-temporal remotely-sensed data for forest cover change detection in the Ghodaghodi lake area of Nepal.

\section{Materials and methods}

\section{Study Area}

Ghodaghodi lake area is situated in the Kailali District of Far-West Nepal. It is the largest inter-connected natural lake system of the Terai Region. It lies along the Mahendra Highway at $28^{\circ} 41^{\prime} 03^{\prime \prime} \mathrm{N}$ and $80^{\circ} 56^{\prime}$ $43^{\prime \prime} \mathrm{E}$ at an altitude of 205 meters above sea level (DNPWC, 2005). The study area (27,460 hectare) encompasses three Village Development Committees (VDCs) of Kailali district namely Darakh, Sandepani and Ramshikharjhala (Fig. 1). The area was recognized as a significant wetland ecosystem supporting an appreciable assemblage of rare, vulnerable, and endangered species, and was designated as a Ramsar Site of International Importance under the Wetlands Convention in August, 2003 (Baral, 1992, Kafle, 2005). Though, the study area is outside the protected area system, its location between two protected areas and extensive forests along the Churia hills makes it an important corridor for wildlife as well as an important habitat for transient migratory species (Kafle, 2005).

Ghodaghodi Lake area was connected with the rest of the country by road only in 1993, following the completion of a bridge over the Karnali River. Since then, several anthropogenic activities that have become apparent around the lake area include: higher grazing pressure, illegal forest products extraction, deforestation and forest degradation, and encroachment (Bhandari, 2009; Diwakar et al., 2009; Gurung, 2003; DNPWC, 2005, Kafle et al., 2007). Like in other parts of the Western Terai, the area has also received human migrants from the mountain zone and experienced greater deforestation, expansion of settlements and cultivation in and around the wetlands (Sah and Heinen, 2001). Rampant deforestation and forest encroachment around the study area have been reported by MCN (2008). However, quantitative and synoptic assessments using standard methods such as remote sensing have been lacking.

\footnotetext{
${ }^{1}$ Assistant Research Officer, Department of Forest Research and Survey, Kathmandu, Nepal. Email: shiva_khanal@yahoo.com
} 


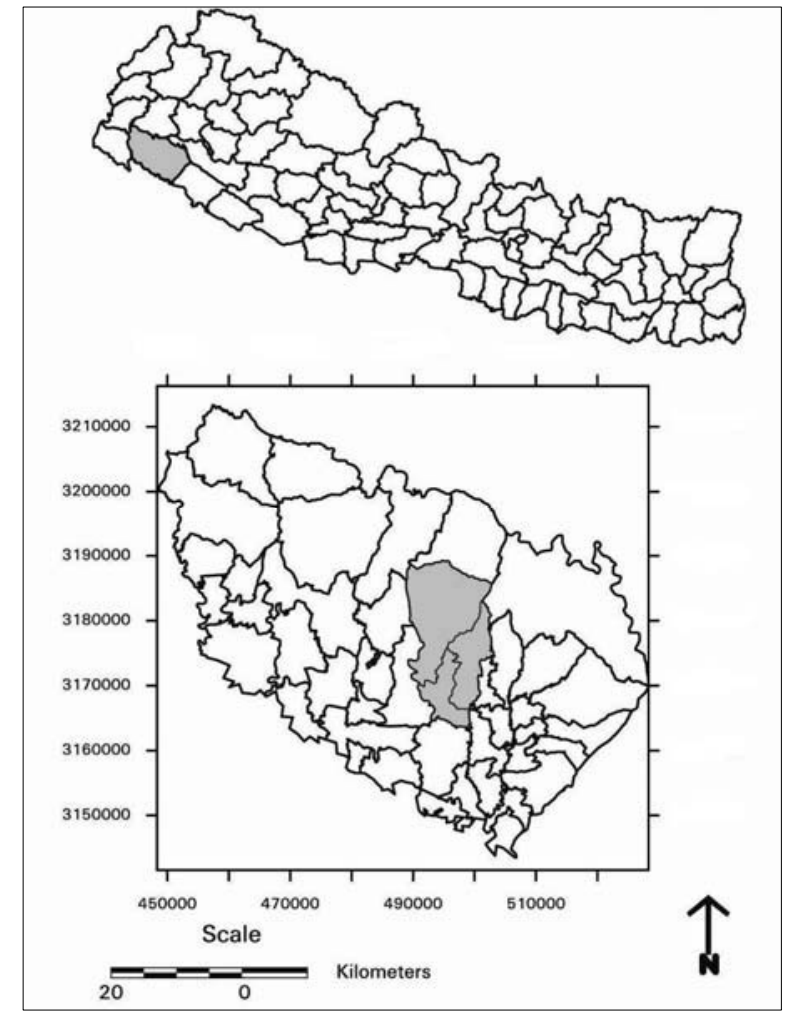

Fig. 1 : Location of Kailali district in Nepal and of the three VDCs of the study area in the district

\section{Data}

Four Landsat images (Table 1) were downloaded from the United States Geological Service, (USGS) Glovis (http://glovis.usgs.gov) and GLCF (http:// glcf.umiacs.umd.edu/) web sites on 12 December 2008 (Figure 2). Fortunately, the ETM+ scene that covered the study area was free from SLC-off defect. All scenes correspond to the peak of the growing season of vegetation, with 9 to 13 years in between acquisitions. High resolution satellite image of $2.5 \mathrm{~m}$ ALOS Pan-sharpened of November 2007, aerial photographs of the year 1964 and 1992, as well as 1:25.000 topo-sheets of the Nepal Survey Department were also acquired from the Department of Forest Research and Survey archives.

\section{Image preprocessing}

One of the important factors determining the accuracy of change detection is the precise geometric

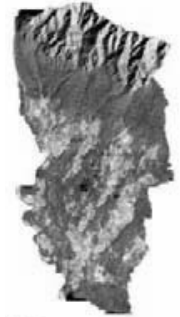

iss

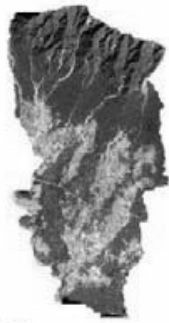

TM

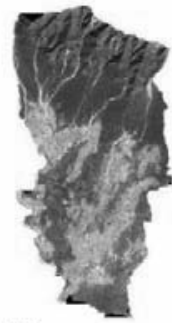

ETM

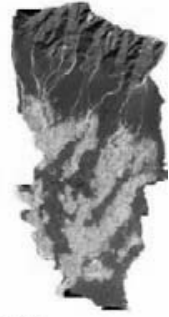

ETM+
Fig. 2 : False Colour Composites (FCC) images of the study area of all dates used in this study

registration between multi-temporal images (Lu et al., 2004). Histogram matching which converts the histogram of one image to resemble the histogram of another is useful for change detection (Erdas, 2008). The resampling of Multi Spectral Scanner (MSS) data to $30 \mathrm{~m}$ pixel was done using cubic convolution. The satellite image set was preprocessed through geometric correction and histogram matching to enhance those images. All images were geometrically corrected to the Everest 1830 datum using the rectified $2.5 \mathrm{~m}$ ALOS pan-sharpened imagery.

\section{Image classification}

Following unsupervised classification based on ISODATA Clustering, field verification and training data acquisition was conducted using five-class output. In the post classification, which is the supervised one based on maximum likelihood, inputs from the verification as well as other secondary maps and information were incorporated. Aerial photographs of the years 1964 and 1992 covering study area were scanned, geo-referenced with respect to imageries and used to aid classification of Landsat Thematic Mapper (TM) and MSS, respectively. Similarly, field data in addition to topo-sheets of Survey Department and November 2007 ALOS Pansharpened images aided classification of ETM and ETM + images. This resulted in classified images each with two classes: forest and non forest. After completing classification of individual images, the majority, $3 \times 3$ filter was run on the classified image to remove the isolated pixels.

Table 1: Landsat dataset used

\begin{tabular}{llllcc}
\hline \multicolumn{1}{c}{ Sensor } & \multicolumn{1}{c}{ Date } & Path/Row & Source & Spatial Resolution (m) & Bands Used \\
\hline ETM + & 2008 Dec 03 & 144/040 & Glovis & 30 & $1,2,3,4$ \\
ETM & 1999 Nov 09 & 144/040 & GLCF & 30 & $1,2,3,4$ \\
TM & 1990 Oct 23 & $144 / 040$ & GLCF & 30 & $1,2,3,4$ \\
MSS & 1977 Jan 23 & 149/041 & GLCF & 57 & $4,5,6,7$ \\
\hline
\end{tabular}




\section{Change detection}

The post classification, change-detection technique of image differencing was applied on subsequent pairs of the classified single date images so that image difference data was obtained for the three time interval (Figure 3).

\section{Accuracy assessment}

Typical accuracy assessments involve verification of the randomly generated locations using reference data. For accuracy assessment, pixels in the classified image were compared to the reference pixels (Erdas, 2008). In this study two major factors undermined this. Firstly the datasets used were not recently acquired except for one. More importantly, there was a lack of reference data to compare the classification of earlier years. The aerial photographs, though distant in time to the image, were the only reference data available. For instance, the MSS image of 1977 was classified and evaluated using aerial photographs of 1964, with the assumption that forest cover change before highway construction was not significant. However, in case of 2008 ETM+, 50 randomly placed points were generated and compared with GPS data from field. This gave a classification accuracy of $96 \%$.

\section{Results and discussion}

Figure 3 shows the result of the post-classification comparison for 3 pairs of images. The figures each represent spatial location of deforested area and forest/non-forest area in each data set. The positive change in forest area was observed to be negligible; and, therefore, those were included in the stable forest class.

The result suggests a decreasing trend for forest cover in the 3 VDCs of Kailali district (Figure 3). Forest cover, as a percent of total land cover, had decreased in the sequence of $75 \%, 70 \%, 65 \%$ and $64 \%$ for the years 1977, 1990, 1999 and 2008, respectively. The loss of forest cover was observed to be highest in the period between 1990 and 1999. The annual rate of change in this period is even higher, since this occurred over only a nine year period (Table 2 ). This trend supports the assumption that impact on forest intensified following the highway link. An almost equal area of forest was lost in the thirteen years between 1977 and 1990. On the other hand, the forest cover loss between 1999 and 2008 was remarkably less than other time frames. This may be due to the fact that, in earlier phases, the rampant

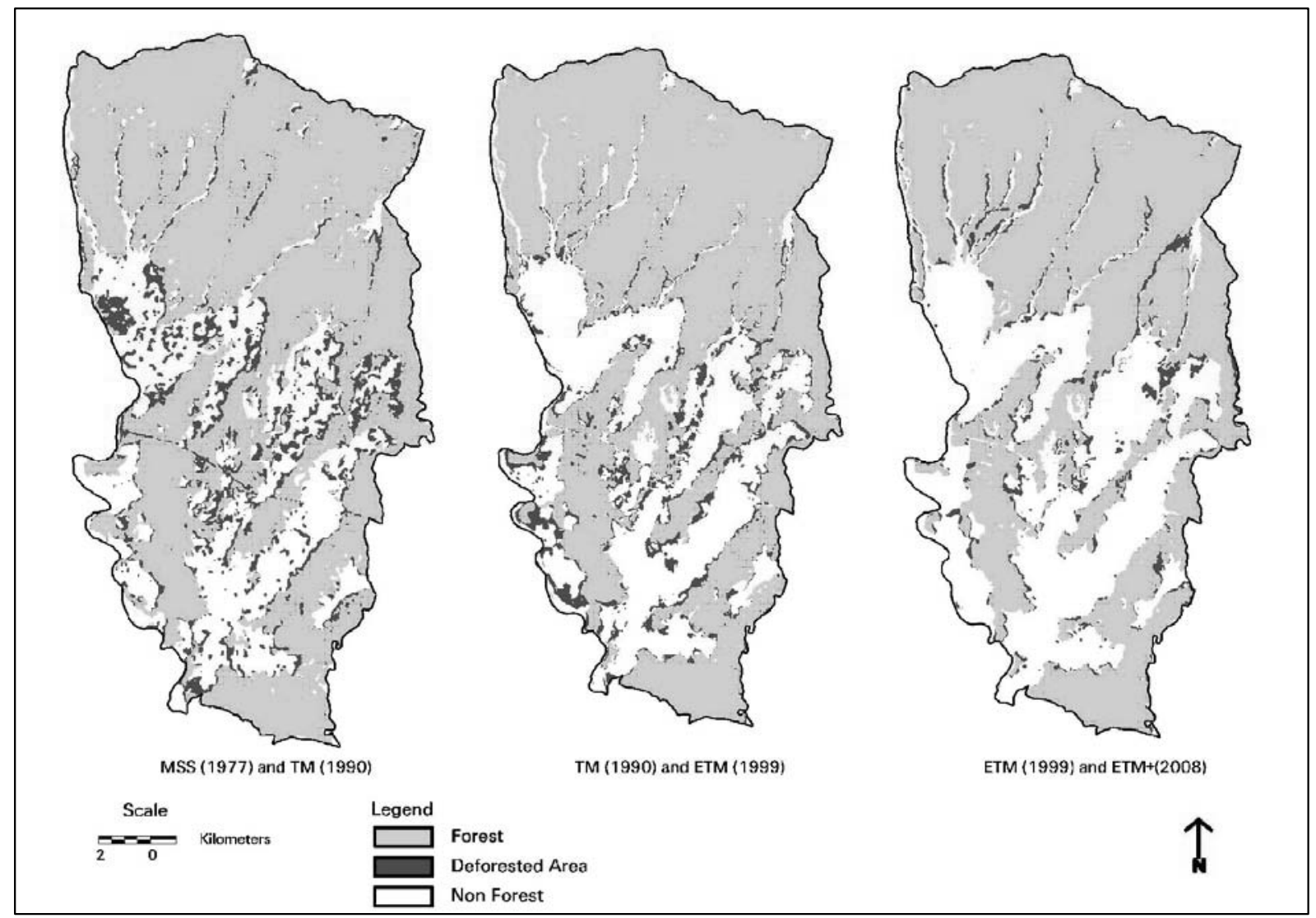

Fig. 3 : Map showing changed and remaining forest between consecutive images for 3 VDCs of Kailali district 
land use change had already destroyed most of the accessible forests. Still, forest loss could be continuous in a very low sustained degree, due to illicit tree removal rather than rapid area clearance.

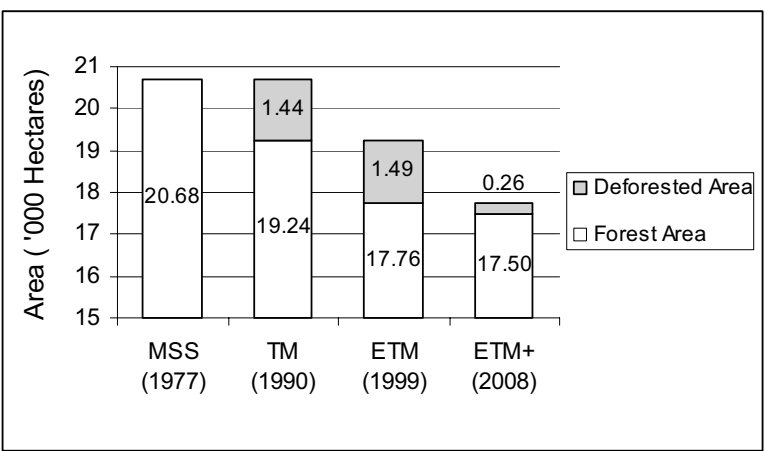

Fig. 4 : Total forest and deforested area in different time frame

The forest cover is shrinking particularly in the southern part of the study area while the hilly part of the north is almost intact with very low forest loss (see Fig 2). According to the observations made during the field visit, the significant portion of change in the north was due to the natural calamity of flood and landslide. In contrast, the southern plain has predominantly high value productive Sal (Shorea robusta) forest, high population density and the resulting activities of cultivation, forest encroachment and illicit tree cutting.

\begin{tabular}{llcc}
\hline Image & $\begin{array}{c}\text { Forest Area } \\
(\% \text { of total area) }\end{array}$ & $\begin{array}{c}\text { Change } \\
\text { (hectares) }\end{array}$ & $\begin{array}{c}\text { Approx. Rate } \\
\text { of Change } \\
\text { (ha/year) }\end{array}$ \\
\hline MSS & $20683.9(75.32)$ & - & - \\
TM & $19244.8(70.08)$ & 1439.1 & 110.70 \\
ETM & $17758.1(64.67)$ & 1486.7 & 165.19 \\
ETM+ & $17500.5(63.73)$ & 257.6 & 28.62 \\
\hline
\end{tabular}

Table 2 : Multi-temporal forest areas, deforested areas and rates of change between 1977 to 2008

\section{Conclusion}

This study revealed that a very important wetland ecosystem in the western Terai of Nepal had lost significant forest cover from 1977 to 2008. Results indicated that forest cover decreased most intensely in the period between 1990 and 1999, following the construction of a major access road. However, the deforestation process, though low in intensity was still being sustained up to 2008. Since the integrity of wetland ecosystem and maintenance of forest cover are interlinked, it is crucial to prevent further forest loss and implement plantation and forest restoration activities.
Although from a very small study area, the results indicated that moderate to high resolution Landsat imagery were useful in landcover studies, for instance, in getting a time series of forest cover data sets. Forest cover change maps derived by classification of the imagery can provide information on the spatial distribution and amount of the change. Reasonably high accuracy can be attained when applied to recent image classification with sufficient reference samples. Knowledge of the detailed dynamics of multiple landuse categories can provide more clear understanding of the changes occurring. Therefore future research should seek to address this.

\section{Acknowledgement}

I would like to express my sincere gratitude to Prof. Dr. Jos Van Orshoven, Department of Earth and Environmental Science, Katholieke Universiteit Leuven, Belgium for his kind comments and suggestions on the concept as well as the draft of this paper. My thanks also go to an anonymous reviewer for the comments.

\section{References}

Baral, H.S. 1992. Ghodaghodi Lake System : A National Treasure, Nepal Bird Watching Club, Kathmandu, Nepal.

Bauer, M.E., Yuan, F and Sawaya, K.E. 2003. "MultiTemporal Landsat Image Classification and Change Analysis of Land Cover in the Twin Cities (Minnesota) Metropolitan Area", paper presented at MutiTemp-2003, Second International Workshop on the Analysis of Multi-temporal Remote Sensing Images, Italy.

Bhandari, B.B. 2009. Wise use of Wetlands in Nepal. Banko Janakari Special Issue: 10-17

Diwakar, J., Bajracharya, S. and Yadav, U.R. 2009. Ecological study of Ghodaghodi Lake. Banko Janakari Special Issue: 18-23

DNPWC. 2005. Fact sheets Wetlands of Nepal Department of National Parks and Wildlife Conservation and WWF Nepal Program, Kathmandu, Nepal.

Erdas, 2008. ERDAS Field Guide Volume Two. Leica Geosystems Geospatial Imaging, LLC

Gurung, S. B. 2003. Education through Learning by Doing. In Doing Education at Wetland Sites: Examples 
and Modalities from Asia. (eds) Bhandari, B., Osamu A., Masahiro T. and Akihiro N. International Institute for Global Environmental Strategies (IGES), Ramsar Center Japan and Mahidol University, Japan.

Kafle, G. 2005. Avifaunal Survey and Vegetation Analysis Focusing on Threatened and NearThreatened Species on Ghodaghodi Lake of Nepal. A Report Submitted to Oriental Bird Club (OBC), United Kingdom.

Kafle, G., Balla, M. K., Baral, H. S. and Thapa, I. 2007. Ghodaghodi Lake area: resources, opportunities and conservation. Damphe 16(3): 16.

Lu, D., Mausel, P., Brondízio, E. and Moran, E. 2004. Change detection techniques. International Journal of Remote Sensing 25(12):2365 -2401
MCN. 2008. Forest encroachment rampant in West Terai. Conservation Watch-Nepal, A Fortnightly Newsletter, Volume-I Issue-8 Jan15, 2008 Media Consultancy Nepal (MCN), Bharatpur, Chitwan, Nepal (Weblink: http:/www.onehornedrhino.org/ download/newsletter/MCN-Conservation $\% 20$ Newsletter_8.pdf, accessed on July 10, 2009)

Ramsar, 2004. List of Wetlands of International Importance Designated by the Contracting Parties. Ramsar, Iran.

Sah, J. P. and Heinen, J. T. 2001. Wetland Resource Use and Conservation Attitudes among Indigenous and Migrant Peoples in Ghodaghodi Lake Area, Nepal. Environmental Conservation 28(4): 345-356. 